\title{
Snares crested penguins Eudyptes robustus population estimates 2000-2013
}

\author{
Johanna A. Hiscock ${ }^{1}$ and B. Louise Chilvers ${ }^{2 *}$ \\ ${ }^{1}$ Southern Islands, Department of Conservation, PO Box 743, Invercargill 9840 \\ ${ }^{2}$ Wildbase, Institute of Veterinary, Animal and Biomedical Sciences, Massey University, Private Bag 1112 , \\ Palmerston North 4442 \\ *Author for correspondence: (Email: b.1.chilvers@massey.ac.nz)
}

Published online: 28 August 2015

\begin{abstract}
New Zealand (NZ) is an internationally significant area for penguins. All NZ penguin species are listed in 'at risk' threat categories. The naturally uncommon Snares crested penguins (Eudyptes robustus), which are restricted to NZ subantarctic islands, are highly susceptible to localised stochastic events and human activities. There has been uncertainty about population size and trends for Snares crested penguins. We surveyed the nest abundance and distribution of Snares crested penguins on Northeast (NE) and Broughton Islands, Snares Island group, from late September to early October in 2008, 2010 and 2013 and compared results with a survey from 2000. Counts of all nests (nests with eggs and total observed nests) within all colonies around the islands were undertaken. In 2008, $19845 \pm 29$ nests with eggs and $24666 \pm 38$ total nests were counted from 111 colonies. In 2010, $25525 \pm 21$ nests with eggs and $30672 \pm 26$ total nests from 117 colonies were counted while in 2013, $25149 \pm 39$ nests with eggs and $29009 \pm 45$ total nests from 119 colonies were counted. Penguin nest numbers at the Snares appear to be stable overall when compared with the 2000 survey, which gave 28396 nests with eggs (direct counts) and 30607 total nests from 112 colonies. However, 2008 appears to be a year with considerably lower numbers of nests compared with other years. This apparently stable population is in contrast to most other crested penguins in the world. Given the extremely restricted distribution of Snares crested penguins and potential for a rapid catastrophic decline, we recommend surveys be continued at regular intervals in order to detect a significant decline and allow management measures to be implemented if needed.
\end{abstract}

Keywords: abundance; long-term monitoring; nest counts; New Zealand subantarctic islands; Snares Islands

\section{Introduction}

The majority of crested penguin (Eudyptes spp.) populations around the world are currently in decline (Cunningham \& Moors 1994; Hilton et al. 2006; Birdlife International 2010; Hiscock \& Chilvers 2014). New Zealand is an internationally significant area for breeding seabirds, particularly penguins, with six species present, four being endemic (Marchant \& Higgins 1990). All NZ penguin species are listed under the NZ threat classification (Townsend et al. 2008) in 'at risk' categories, due to being naturally uncommon, having restricted natural distributions or small and declining populations (Robertson et al. 2012). Erect-crested (E. sclateri) and Snares crested penguins (E. robustus) are both naturally uncommon species with distributions restricted to the NZ subantarctic islands. Fishing bycatch/competition, geological exploration, tourism, pollution (oil, fuel, rubbish) and introduced predators are all factors affecting penguin species (Doole 1998). Small restricted populations are highly susceptible to localised stochastic events and human activities (Kendall \& Wittmann 2010). If these populations are impacted by negative external factors, these species could quickly become endangered or extinct.

The Snares crested penguin is only known to breed on four islands in the Snares group $\left(48^{\circ} \mathrm{S}, 166^{\circ} 35^{\prime} \mathrm{E}\right.$; Fig. 1). They are a medium-sized crested penguin with body length of 50 to $60 \mathrm{~cm}$ and average mass of $2.8 \mathrm{~kg}$ for females and $3.4 \mathrm{~kg}$ for males (Marchant \& Higgins 1990). The breeding period of Snares crested penguins is well defined, with adults arriving in the first three weeks of September, the males arriving approximately a week before the females (Warham 1974). Nests are generally scooped out hollows lined with mud or peat mixed with twigs, stones and bones. Two eggs are laid on average 4.5 days apart in late September/early October. For the first 2 weeks after egg laying, both males and females remain at the nest, although the females predominantly incubate the egg during this time (Warham 1974). After the first 2 weeks, males leave to forage for approximately 2 weeks while the females continue incubating (Amey et al. 2001, unpubl. report, see Appendix S1; hereafter the 2001 Amey Report). They then swap, allowing females to forage for about a week while males incubate, with females returning to coincide with egg hatching (Mattern 2007).

With only two previous breeding population estimates for Snares crested penguins, there has been uncertainty about population size and long-term trend. In 1985/86 the total breeding population of Snares crested penguins was estimated at 23250 pairs based on counts of chicks and $73 \%$ breeding success per pair (Johns \& Miskelly 1986). The 2001 Amey Report (Appendix S1) undertook a full census of NE Island for Snares crested penguins in October 2000. Direct counts of 25 870 breeding nests and 23659 nests with eggs were recorded for NE Island. An estimate (not count) of 4737 nests was made for Broughton Island, giving a total for the two main Snares Islands of 30607 nests or 28396 nests with eggs.

The purpose of this study was to monitor variability in Snares crested penguin colonies and obtain accurate population estimates for the two main breeding islands (NE and Broughton Islands; $99 \%$ of the estimated population; Appendix S1) from 2008 to 2013. We then compared our 2008-2013 data with findings from previous surveys to clarify the overall population trend. 


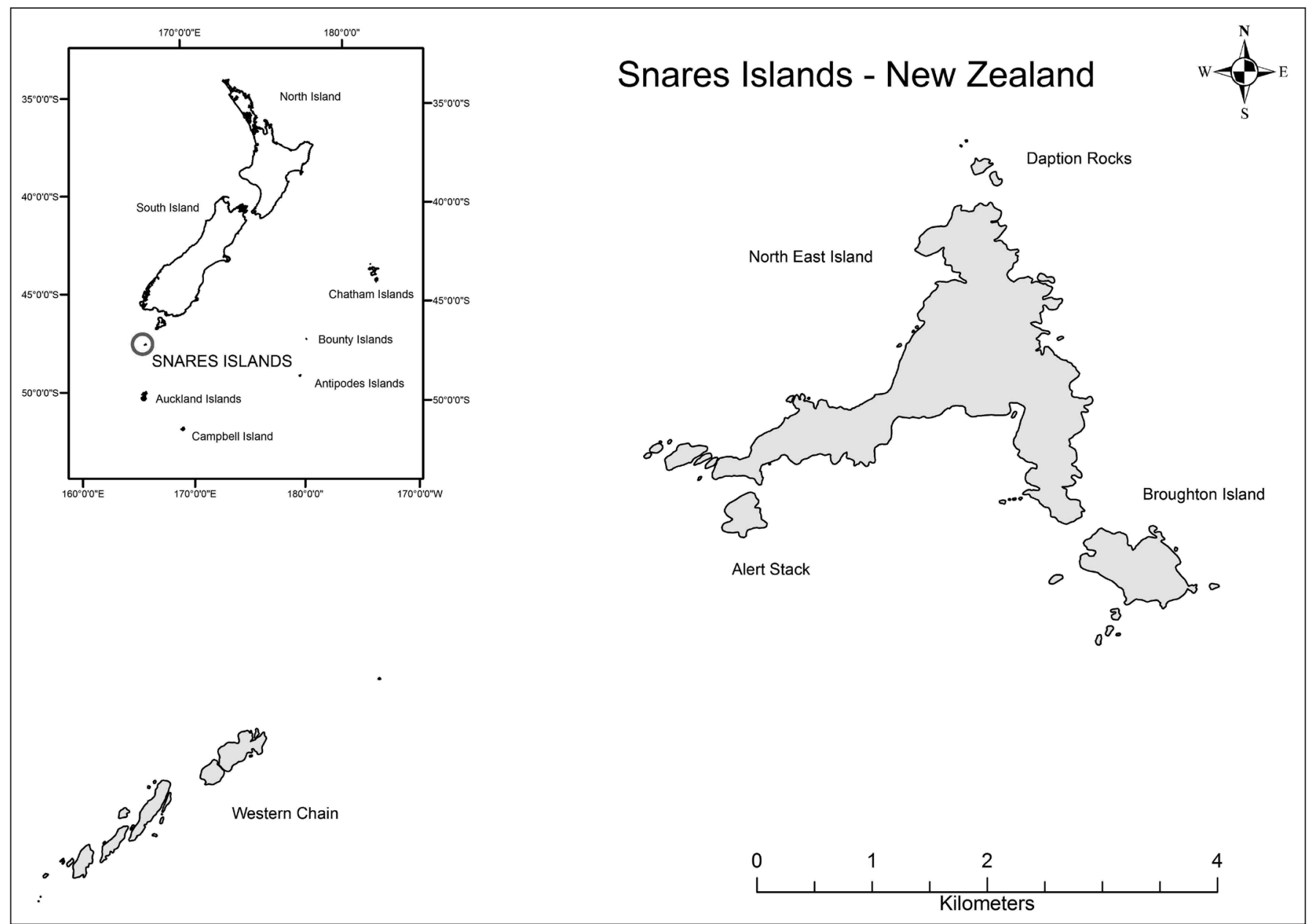

Figure 1. Map of the Snares Islands groups, showing their location in relation to the South Island of New Zealand and the other subantarctic islands.

\section{Material and Methods}

The Snares are the closest subantarctic group to mainland NZ $\left(48^{\circ} \mathrm{S}, 166^{\circ} \mathrm{E} ; 100 \mathrm{~km}\right.$ south of Stewart Island), with Snares crested penguins breeding on four of its islands, NE(280 ha) and Broughton Islands (48 ha; Fig. 1), and Rima and Toru Islands on the western chain islands, four kilometres SW of NE Island (not shown on map). The Snares crested penguin colonies are sited on bare rock, in open areas surrounded by tussock grass or forest, or under a canopy of Olearia lyallii, Brachyglottis stewartiae or Hebe elliptica. Ground count surveys of NE and Broughton Islands were undertaken between 1 October and 15 October 2008, 30 September and 9 October 2010, and 30 September and 12 October 2013 to coincide with the end of the egg laying period, when the maximum number of pairs attempting to breed would be present (Appendix S1). Ground counts were not undertaken on Rima or Toru Islands because peak laying on these islands is approximately six weeks after NE and Broughton Islands (Miskelly et al. 2001).

Counts were made of: 1) 'egg' nests, defined as where an egg/s were seen, or a bird or bird pair were in an incubating position; or 2) empty nests, being nests that were 'an obvious this year's nest mound/scrape with or without birds' (Amey Report, Appendix S1). This division was made because a bird/ pair incubating an egg are obviously breeding, whereas an empty nest may belong to birds not capable of breeding but trying to breed (i.e. old or infertile, but still building nests, or young birds prospecting for a nest and mate). In some cases, empty nests may also be early failed breeders still present in the colony or late breeders.

Two methods of counting were used to ground count all nests. The majority of colonies (c. 80\%) were 'tally' counted with two people visually counting nests, registering nests with an egg and empty nests on separate tally counters, and the counts averaged. Approximately 25 colonies were 'paint' counted because of the difficulty of counting the colonies due to high vegetation cover and large size of the colony. Every nest visited in these colonies was counted on the tally counters (as above) and marked with a paint mark beside the nest. Ten per cent of these colonies were then resampled, checking all nests for paint marks. After the recount, the total count was adjusted for nests not painted or those painted twice. Any colony larger than 100 nests, regardless of whether they were tally or paint counted, was divided into small, easy-to-count areas by painting lines with raddle stock marker aerosols ('Telltail', FIL, Mount Maunganui, NZ). The raddle was water soluble and was not visible a week after application on most surfaces.

Colonies in 2008 were originally located using GPS locations from the 2000 survey (see Appendix S1) and these GPS locations were updated during each consecutive survey 
because 1) more accurate locations could be obtained due to improved GPS technology, 2) colonies moved locations, 3) new colonies were established or 4) colonies were abandoned.

As outlined in the 2001 Amey Report (Appendix S1), we defined a colony as 'an area the penguins treat as one nesting area, where birds move between or hang around between areas, but not including penguin paths or through traffic'. This definition fitted better than using an arbitrary distance, e.g. $20 \mathrm{~m}$, to separate colonies, as some colonies were quite close together but still distinct, while others were separated by a physical barrier, e.g. rock outcrop or wet area, but were essentially one colony. Colony names and numbering system were continued on from the 2001 Amey Report (Appendix S1). Colonies were numbered sequentially when found and were grouped by the catchment and landing site from which the colony was accessed. If the separation of a smaller colony from a larger colony was distinct but the vegetation and environment suggested it was a remnant of a nearby colony, or if the smaller colony was very close, it was considered a sub-colony and numbered accordingly with the established colony number and a suffix. If the new colony was distinct from any current or historical colonies it was allocated an entirely new number.

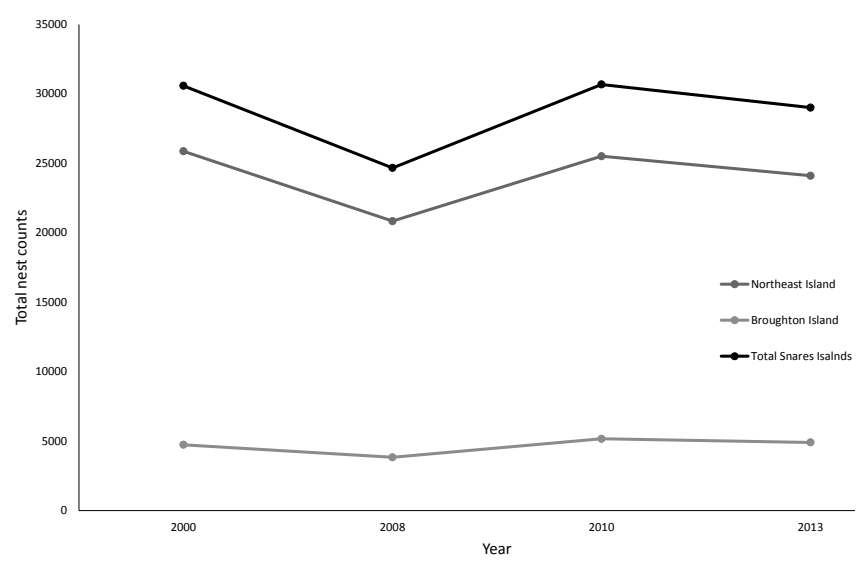

Figure 2. Total nest counts of Snares crested penguins from Northeast and Broughton Islands, and The Snares combined from 2000 to 2013.

\section{Results}

On Broughton Island, 30 colonies were counted in 2008, 29 colonies in 2010 and 28 colonies in 2013. Many of these colonies split between years and were counted as sub-colonies. The Broughton Island total nest counts showed no overall trend and changed substantially only between 2008 and 2010 , with $25 \%$ more nests found in direct counts in 2010 (Table 1, Fig. 2). There were $6 \%$ fewer nests counted in 2013 than 2010 , though this change was predominately caused by higher numbers of empty nests in 2010 than in 2013 (Table 1, Fig. 2).

On NE Island, 111 colonies were counted in 2008, 117 in 2010 , and 119 in 2013; these colony numbers were very similar to the 112 colonies counted in 2000. Between the 2000 and 2013 nest counts, 12 colonies were lost, while 19 new colonies were formed. There were many changes within colonies, with colonies expanding and contracting in size. NE Island total nest direct counts showed no overall trend, but in 2008 there were $19 \%$ fewer nests counted than in 2000 and $18 \%$ more nests counted in 2010 than in 2008 (Table 1, Fig. 2).

Overall, the Snares crested penguins total nest direct counts between 2000 and 2013 were stable, although all nest counts were lower in 2008 (Table 1, Fig. 2). There was a slight decrease in numbers of nests with eggs across the 13 years of this research (Table 1, Fig. 2).

\section{Discussion}

The purpose of this research was to monitor Snares crested penguins breeding population size for the two main breeding islands (NE and Broughton Islands) from 2008 to 2013. The quantitative estimate we obtained indicates an overall stable population between 2000 and 2013, but with an anomalous year with a substantial drop in numbers in 2008. Although it is difficult to compare population estimates from this study with previous studies that counted chicks and not nests (Johns \& Miskelly 1986; Tennyson 1987), these studies also report the relative stability of breeding numbers for Snares crested penguins. There are no survey data to determine whether the breeding population has been higher or lower historically and the only way to assess this would be through genetic analysis (Collins et al. 2014; Robertson 2015).

Table 1. Total nest counts of nests with eggs and empty nests of Snares crested penguins from Northeast and Broughton Islands, and The Snares combined from 2000, 2008, 2010 and 2013.

\begin{tabular}{|c|c|c|c|c|}
\hline $\begin{array}{l}\text { Broughton Island } \\
\text { Nests with eggs } \\
\text { Empty nests } \\
\text { Total }\end{array}$ & $2000 *$ & $\begin{array}{r}\mathbf{2 0 0 8} \\
3375 \pm 20.3 \\
457 \pm 8.0 \\
3832 \pm 21.8\end{array}$ & $\begin{aligned} \mathbf{2 0 1 0} \\
4358 \pm 4.3 \\
805 \pm 5.1 \\
5163 \pm 6.7\end{aligned}$ & $\begin{array}{r}\mathbf{2 0 1 3} \\
4433 \pm 29.8 \\
472 \pm 7.8 \\
4904 \pm 30.8\end{array}$ \\
\hline $\begin{array}{l}\text { Northeast Island } \\
\text { Nest with eggs } \\
\text { Empty nests } \\
\text { Total }\end{array}$ & $\begin{array}{rl}23 & 659 \\
2 & 211 \\
25 & 870\end{array}$ & $\begin{aligned} 16470 & \pm 20.7 \\
4364 & \pm 23.4 \\
20834 & \pm 31.2\end{aligned}$ & 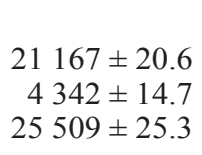 & $\begin{array}{r}20716 \pm 25.7 \\
3389 \pm 19.7 \\
24105 \pm 32.4\end{array}$ \\
\hline $\begin{array}{l}\text { Snares Islands } \\
\text { Northeast Island } \\
\text { Broughton Island } \\
\text { Egg nest only total } \\
\text { Total }\end{array}$ & $\begin{array}{r}25870 \\
4737 \\
28416 \\
30577\end{array}$ & 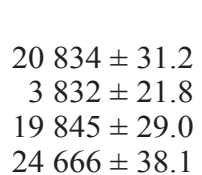 & $\begin{array}{r}25509 \pm 25.3 \\
5163 \pm 6.7 \\
25525 \pm 21.0 \\
30672 \pm 26.2\end{array}$ & 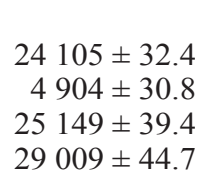 \\
\hline
\end{tabular}

* 2001 Amey Report (Appendix S1), Table 4 direct count data - Broughton Island data are estimates not counts. 
When making comparison between this study and that of the 2001 Amey Report (Appendix S1) it must be noted that the Report presented results from direct counts and 'corrected' counts. To obtain corrected counts, several colonies were monitored from the beginning to the end of the two-week sampling period and the numbers of new or failed nests were compared with the original count undertaken on 9 October 2000. From this, a correction factor was added to those colonies counted after 9 October. This correction monitoring or calculation was undertaken in 2008, but similarly to the 2001 Amey Report (Appendix S1), gave negligible differences compared with direct counts, so was not undertaken in 2010 or 2013.

This research confirms the assumption of the 2001 Amey Report (Appendix S1) that the Broughton Island population makes up approximately $20 \%$ of the Snares crested penguin breeding population (16\% of total nest counts in 2008 , and $17 \%$ in both 2010 and 2013, Table 1). Therefore, it should be surveyed when NE island is being surveyed because it does comprise an important proportion of the population.

It is not known why the number of nesting Snares crested penguins reduced in 2008; however, given the return to previous numbers within two years, it is likely to have been caused by fewer birds returning to breed that year, rather than a decrease of individuals in the population. A strong El Niño season in 2007 may have resulted in a later onset of the spring bloom and subsequent reduction in oceanic productivity, which could account for the decrease in nests in 2008. Similar breeding declines were seen in other pelagic bird populations in NZ and were attributed to the strong 2007 El Niño season (Graeme Taylor, Department of Conservation, pers. comm.). Penguins are generally thought to be sensitive to climate change (Barbraud \& Weimerskirch 2001; Jenouvrier et al. 2005; Trathan et al. 2006; Boersma 2008; Ainley et al. 2010). The decline in rockhopper penguins on Campbell Island/Motu Ihupuku is thought to be due to increases in sea temperature leading to changes in food distribution and abundance (Cunningham \& Moors 1994; Morrison et al. 2015). The frequency of years with El Niño conditions has increased in the past decades and could continue to have a negative impact on the Snares population, particularly if several El Niño events occurred in short succession (Cai et al. 2014). This could have a long-term effect on the population, by decreasing the recruitment of birds into the breeding populations.

Overall, the findings that Snares crested penguins populations appear to be stable is in contrast to most other crested penguins in the world. For example, the population of western rockhopper penguins (E. chrysocome) on the Falkland Islands in the South Atlantic Ocean was estimated at approximately 3 million breeding pairs in the early 1930s, but had declined to approximately 275000 pairs by the $2000 / 01$ breeding season (Pütz et al. 2002). Likewise, the population of northern rockhopper penguins (E. moseleyi) breeding on Amsterdam Island in the Indian Ocean declined at a rate of $2.7 \%$ per year between 1971 and 1993, decreasing from 58000 pairs to 24890 pairs (Guinard et al. 1998). A similar trend has also been observed in NZ, with numbers of eastern rockhopper penguins breeding on Campbell Island/Motu Ihupuku declining from an estimated 1.6 million pairs in the early 1940 s to 103100 pairs in 1984-87 (Cunningham \& Moors 1994). Erect-crested and eastern rockhopper penguins at the Antipodes Islands have shown a 23\% decline in the number of penguin nests between 1995 and 2011 (Hiscock \& Chilvers 2013).
In the long term, the greatest threat to Snares crested penguins is the small size of the island group on which they breed (328 ha), making them vulnerable to disastrous stochastic events such as tsunamis, earthquakes or oil spills (Taylor 2000; BirdLife International 2010). On NE Island, which holds around $85 \%$ of the world's population, Snares crested penguins use only a few landing sites along the east coast (Fig. 1). The loss of these sites due to earthquake movements or landslides would have a devastating effect on the species. Similarly, an oil spill within the vicinity of the landing sites would have severe consequences, especially during the height of the breeding season, or during moulting. Ruoppolo et al. (2012) gives an account of how thousands of moulting northern rockhopper penguins were killed on Nightingale Island at Tristan da Cunha in the Atlantic Ocean due to an oil spill from a grounded ship. Tristan da Cunha was a stronghold for the endangered northern rockhopper species with an estimated 25000 breeding pairs (BirdLife International 2012).

\section{Future census}

Given the restricted distribution of Snares crested penguins and therefore their susceptibility to stochastic events, we recommend a survey be undertaken every 5 years for this species, with a survey repeated within 2 years if a substantial decrease, as seen in 2008, is observed. Future censuses should be carried out at a similar time in the year to coincide with the end of the egg laying period $(99.5 \%$ of nests had been laid by 6 October 2000; Amey Report, Appendix S1), when the maximum number of breeding pairs are in the colony. The surveys should not be undertaken after chicks have hatched, as the number of failed nests would be higher than when carried out at the egg stage due to the predation of chicks by skua (Stercorarius antarcticus). Also, by 16 October, locating and counting penguin colonies becomes more difficult (Amey Report, Appendix S1). The colonies became very quiet because $80 \%$ of male penguins had departed for sea, leaving the female bird incubating and it is possible to pass close without hearing the colony (Amey Report, Appendix S1). Similarly, single females are easily scared from nests leaving eggs vulnerable to predation and making counting more difficult.

A separate census of the Western chain penguin population is recommended, but given it is likely to be less than $2 \%$ of the entire population and the six week delay in the breeding cycle of these birds, it is not as high a priority as NE and Broughton Islands. However, because of this six week delay in breeding, there may be interesting comparisons to be made between these small populations and the main population. A difference in breeding timing may indicate different foraging patterns and therefore a differing susceptibility to environmental changes. Aerial photography survey may be possible on these treeless islands, but would ideally be ground truthed to confirm timing of breeding.

\section{Conclusions}

The findings of this study indicate that the population of Snares crested penguins appears to have been stable between 2000 and 2013 , but with a reduction in animals breeding in 2008. The survey method outlined in this paper and in the 2001 Amey Report provides baseline information, general colony locations and a methodology for monitoring this small, geographically restricted, threatened seabird species. Given the dynamic nature of the colonies across both NE and Broughton islands, 
whole island censuses are recommended during each survey. However, if time is restricted, efforts should be concentrated on NE Island. A monitoring programme carried out every 5 years, with more frequent surveys if nesting numbers are abnormally low (as for 2008), should ensure any long-term population trends will be observed, supporting the need for mitigation strategies.

\section{Acknowledgements}

This work was conducted and funded by the Southern Islands Area Office of the New Zealand Department of Conservation (DOC). We thank Paul Sagar and NIWA for collaboration and assistance in sharing transport to the Snares Islands. Also Dave Houston, Dan Palmer and Gilly Adams, for field assistance with the 2008 survey; Sue Lake, Richard Ewans and Liz Metsers for field assistance with the 2010 survey; and Kathryn Pemberton, Paul Sagar and Kyle Morrison for field assistance with the 2013 survey. We sincerely thank Henk Haazen and RV Tiama for transport, and P. McClelland and two anonymous reviewers all provided helpful, critical reviews of the manuscript. We thank the Department of Conservation and Jacinda Amey for allowing us to reproduce their 2001 report, Census of the Snares crested penguin (Eudyptes robustus) breeding population, as supplementary material for this paper.

\section{References}

Ainley D, Russell J, Jenouvrier S, Woehler E, Lyver P, Fraser WR, Kooyman GL 2010. Antarctic penguin response to habitat change as Earth's troposphere reaches $2^{\circ} \mathrm{C}$ above preindustrial levels. Ecological Monographs 80: 49-66.

Barbraud C, Weimerskirch H 2001. Emperor penguins and climate change. Nature 411: 183-186.

BirdLife International 2010. Rockhopper penguins: a plan for research and conservation action to investigate and address population changes. Proceedings of an international workshop, Edinburgh, 3-5 June 2008. P. 32.

BirdLife International 2012. First assessment of Endangered Northern Rockhopper Penguins since 2011 oil spill. http:// www.birdlife.org/community/2012/02/first-assessmentof-endangered-northern-rockhopper-penguins-since2011-oil-spill/ (accessed 14 July 2015).

Boersma PD 2008. Penguins as marine sentinels. BioScience 58: 597-607.

Cai W, Borlace S, Lengaigne M, van Rensch P, Collins M, Vecchi G, Timmermann A, Santoso A, McPhaden MJ, Wu L, England MH, Wang G, Guojian W, Guilyardi E, Jin F-F 2014. Increasing frequency of extreme El Niño events due to greenhouse warming. Nature Climate Change 4: 111-116.

Collins CJ, Rawlence NJ, Prost S, Anderson CNK, Knapp M, Scofield RP, Robertson BC, Smith I, Matisoo-Smith EA, Chilvers BL, Waters JM 2014. Extinction and recolonization of coastal megafauna following human arrival in New Zealand. Proceedings of the Royal Society B: Biological Science 281: 20140097. doi: 10.1098/ rspb.2014.0097

Cunningham DM, Moors PJ 1994. The decline of Rockhopper Penguins Eudyptes chrysocome at Campbell Island, Southern Ocean and the influence of rising sea temperatures. EMU 94: 27-36.
Doole P 1998. Conservation Management Strategy Subantarctic Islands 1998-2008. New Zealand, Department of Conservation.

Forcada J, Tranthan PN, Reid K, Murphy EJ, Croxall JP 2006. Contrasting population changes in sympatric penguin species in association with climate warming. Global Change Biology 12: 411-423.

Guinard E, Weimerskirch H, Jouventin P 1998. Population changes and demography of the northern Rockhopper Penguin on Amsterdam and Saint Paul Islands. Colonial Waterbirds 21: 222-228.

Hilton GM, Thompson DR, Sagar PM, Cuthbert RJ, Cherel Y, Bury S 2006. Astable isotopic investigation into the causes of decline in a sub-Antarctic predator, the rockhopper penguin Eudyptes chrysocome. Global Change Biology 12: 611-625.

Hiscock J, Chilvers BL 2014. Declining southern Rockhopper andErectCrested penguins, Antipodes Island, NewZealand. New Zealand Journal of Ecology 38:124-131.

Jenouvrier S, Barbraud C, Weimerskirch H 2005. Long-term contrasted responses to climate of two Antarctic seabird species. Ecology 86: 2889-2903.

Johns PM, Miskelly CM 1986. Snares Island crested penguin. Snares Island expedition report 1985-86. Christchurch, New Zealand, University of Canterbury.

Kendall BE, Wittmann ME 2010. A stochastic model for annual reproductive success. The American Naturalist 175: 461-468.

Marchant S, Higgins PJ 1990. Handbook of Australian, New Zealand and Antarctic Birds. Melbourne, Oxford University Press.

Mattern T 2007. Marine ecology of offshore and inshore foraging penguins: The Snares penguin Eudyptes robustus and yellow-eyed penguin Megadyptes antipodes. $\mathrm{PhD}$ thesis, University of Otago, Dunedin, New Zealand.

Miskelly CM, Sagar PM, Tennyson AJD, Scofield RP 2001. Birds of the Snares Islands, New Zealand. Notornis 48: $1-40$.

Morrison KW, Battley PF, Sagar PM, Thompson DR 2015. Population dynamics of Eastern Rockhopper Penguins on Campbell Island in relation to sea surface temperature 1942-2012: current warming hiatus pauses a long-term decline. Polar Biology 38:163-177.

PützK, Ingham RJ, Smith JG, Luthi BH 2002. Winter dispersal of rockhopper penguins Eudyptes chrysocome from the Falkland Islands and its implications for conservation. Marine Ecology Progress Series 240: 273-284.

Robertson BC 2015. Is management limiting the recovery of the New Zealand sea lion Phocarctos hookeri? Polar Biology 38: 539-546. doi 10.1007/s00300-014-1619-2

Robertson HA, Dowding JE, Elliott GP, Hitchmough RA, Miskelly CM, O’Donnell CFJ, Powlesland RG, Sagar PM, Scofield RP, Taylor GA 2012. Conservation status of New Zealand birds, 2012. New Zealand Department of Conservation Threat Classification Series http://www.doc. govt.nz/Documents/science-and-technical/nztcs4entire. pdf (accessed 14 July 2015).

Ruoppolo V, Woehler EJ, Morgan K, Clumpner C 2012. Wildlife and oil the Antarctic: a recipe for cold disaster. Polar Record 48: 1-13. doi:10.1017/S0032247411000763

Taylor G A 2000. Action plan for seabird conservation in New Zealand. Part A: Threatened seabirds. Threatened Species Occasional Publication No. 16. Wellington, New Zealand, Department of Conservation. 
Tennyson AJD 1987. Snares crested penguin Eudyptes robustus Census. Snares Island expedition report 1986-87. Christchurch, New Zealand, University of Canterbury.

Trathan PN, Murphy EJ, Forcada J, Croxall JP, Reid K, Thorpe SE 2006. Physical forcing in the southwest Atlantic: ecosystem control. In: Boyd IL, Wanless S, Camphuysen CJ eds Top predators in marine ecosystems. Cambridge, Cambridge University Press.

Townsend AJ, de Lange PJ, Duffy CAJ, Miskelly CM, Molloy J, Norton D 2008. New Zealand Threat Classification System manual. Wellington, Department of Conservation.

Editorial board member: Jo Monks

Received 31 July 2014; accepted 22 June 2015

\section{Supplementary Material}

Additional supporting information may be found in the online version of this article:

Appendix S1. Amey et al. (2001). Snares Penguin Survey Report.

The New Zealand Journal of Ecology provides online supporting information supplied by the authors where this may assist readers. Such materials are peer-reviewed and copy-edited but any issues relating to this information (other than missing files) should be addressed to the authors. 